\title{
Young people who access harm-advocating online content: A four- country survey
}

\author{
Atte Oksanen ${ }^{1}$, Matti Näsi ${ }^{2}$, Jaana Minkkinen ${ }^{3}$, Teo Keipi ${ }^{4}$, Markus Kaakinen $^{5}$, Pekka Räsänen ${ }^{6}$ \\ ${ }^{1,3,5}$ School of Social Sciences and Humanities, University of Tampere, Tampere, Finland \\ ${ }^{2,4,6}$ Department of Social Research, University of Turku, Turku, Finland
}

\begin{abstract}
This study examined the commonality of exposure to sites that advocate eating disorders, self-injury and suicide among American, British, German and Finnish respondents ( $N=3565$ ) aged 15-30 (age $M=23.06,50.15 \%$ male). The analysis focused on both cross-national and socio-demographic differences and on user characteristic including happiness, previous online and offline victimization and online user activity. German respondents had significantly lower levels of exposure to harm-advocating online content than respondents in the three other countries. Females were more likely to be exposed to eating disorder content, while males witnessed more selfinjury and suicide content across all four countries. Younger respondents were more likely to be exposed to such material. In addition, other socio-demographic background variables (not living with parents, immigrant background, city residence, online activity) and personal characteristics associated with negative self-schemata were significant predictors of exposure to such content. The findings indicate that those facing difficulties in their everyday life are at higher risk of accessing online sites that may foster unhealthy behavior.
\end{abstract}

Keywords: Internet; social media; eating disorders; suicide; self-injury; youth; victimization

\section{Introduction}

The Internet is home to various self-help and support groups that aim to provide positive feedback and encourage wellbeing for their members (Barak, Boniel-Nissim, \& Suler, 2008; Obst \& Stafurik, 2010; Tanis, 2007). However, despite the vast amount of positive content online, the nature of the Internet as user-generated also facilitates various extreme and pathological communities that share information about ways to deliberately harm or hurt oneself. Such material is created and distributed within small communities and is readily accessible to those seeking such exposure. In this study, we refer to such content as harm advocating online content.

Much of the discussion about harm-advocating content has concentrated on eating disorders. Pro-anorexia (proana) and pro-bulimia (pro-mia) sites and online communities are publicly available, interactive and often promote "thinspiration" ('inspirational' pictures of extremely thin bodies) (Borzekowski, Schenk, Wilson, \& Peebles, 2010; Juarascio, Shoaib, \& Timko, 2010; Norris, Boydell, Pinhas, \& Katzman, 2006; Oksanen et al., 2015). They are also globally searched and accessed with the help of online search engines (Lewis \& Arbuthnott, 2012). In addition to sites and communities dedicated to eating disorders, content concerning non-suicidal self-injury 
(e.g. self-mutilation) is frequently viewed on sites such as YouTube (Lewis, Heath, St Denis, \& Noble 2011; Lewis, Heath, Michal, \& Duggan, 2012). Pro-suicide sites and communities portray more extreme versions of the online world, uniting people who have suicide ideation and plans (Biddle, Donovan, Hawton, Kapur, \& Gunnell, 2008; Dunlop, More, \& Romer, 2011; Luxton, June, \& Fairall, 2012).

Notably, few preceding studies have assessed the prevalence of accessing harm-advocating online content among online users. According to the EU Kids Online study, 10\% of European children aged 11 to 16 had visited pro-eating disorder sites, 7\% had seen self-harm sites, and $5 \%$ had seen suicide sites (Livingstone, Haddon, Görzig, \& Ólafsson, 2011). Dunlop and colleagues' (2011) survey of young Americans aged 14 to 24 reveals that $59 \%$ have drawn information about suicide from online sources. Despite these studies, Livingstone and Smith (2014) note that significant gaps in the research remain. These gaps are largely a result of the rapid changes in the technological environment. Different forms of online risks remain a relatively new research topic and as such there is a need for more empirical research regarding the different associations of online risks on, for example, wellbeing. Much of the earlier research is based on studies with children (e.g. Livingstone et al., 2011; Mitchell, Finkelhor, Wolak, Ybarra, \& Turner, 2011). Thus there is a lack of cross-national studies concerning characteristics of adolescents and young adults who are perhaps the most significant audience of harm advocating online content, due to high prevalence of self-harming behavior and eating disorders during this age (see Fairburn \& Harrison, 2003; Hawton, Saunders, \& O'Connor, 2012). In addition, we do not know much about their socio-demographic background or how earlier online and offline victimization experiences and low levels of subjective happiness associate with seeing such material. This is significant because lower level of happiness has been considered as a risk factor for self-harming behavior (Koivumaa-Honkanen, Honkanen, Koskenvuo, \& Kaprio, 2003).

The aim of this article is to advance our understanding of young people encountering harm-advocating online content. We will focus on exposure to self-harm, suicide and eating disorder content. The article focuses on three different age phases, namely late adolescence (age 15-18), emerging adulthood (age 19-25) and young adults (age 26-30). During this period young people face rapid life events and instability and the incidence of psychopathology increases (Arnett 2000; Schulenberg \& Zarrett, 2006). Thus, during these ages, Internet users are a potential risk group for exposure to harmful content. We look for both risk factors in socio-demographic background variables, as well as in personal characteristics including happiness and previous victimization experiences. Given this focus, the article first reviews previous research on harm-advocating online content and factors of online risk behavior, followed by a review of a theoretical framework based on the concept of negative self-schemata.

\section{Anti-Health Phenomenon Online}

Harm-advocating online content is by definition anti-health due to its promotion of ideas that are both physically and psychologically harmful, as determined by the mainstream of scientific knowledge. The focus of this article is on three types of harm-advocating content, namely self-injury, suicide and eating disorders. Each of these three types of online content serves as self-focused phenomena and thus are related to one another in fundamental ways. Eating disorders, for example, have been found to be associated with higher suicide rates (e.g. Portzky, van Heeringen, \& Vervaet, 2014; Swanson, Crow, Le Grange, Swendsen, \& Merikangas, 2011). Furthermore, all of these behaviors tend to be affected socially through peer influence processes (Brechwald \& Prinstein, 2011).

Eating disorder content: Of the three forms of harm-advocating online material discussed here, pro-ana is perhaps the most well-known by both people in general as well as by members of harm advocating networks (Brotsky \& Giles, 2007; Gavin, Rodham, \& Poyer, 2008; Norris et al., 2006). According to Custers and Van den Bulck (2009), almost 13 per cent of girls and nearly 6 per cent of boys aged 13, 15 and 17 had visited proanorexia websites. According to the study, girls who visited such sites had a higher drive for thinness and perfectionism as well as a more negative perception of their appearance. Similarly, members of pro-ana communities have also been found to report high levels of disordered eating (Harper, Sperry, \& Thompson, 2008; Rodgers, Skowron, \& Chabrol, 2012). 
Suicide content: online pro-suicide content has raised much discussion during the 2000s (Biddle et al., 2008; Luxton et al., 2012; Rajagopal, 2004), yet studies point out that most of the material concerning suicide does not actually advocate it. A study based on web search engines by Recupero, Harms, and Noble (2008) found that only 11 per cent of suicide web hits were actually pro-suicide. Kemp and Collings (2011) assessed the visibility of such material by using a sophisticated web crawling data collection strategy. They found pro-suicide sites to be a marginal phenomenon compared to sites dedicated to suicide prevention. A review of 14 empirical studies showed that the Internet could have a positive and a negative influence on young people at risk of self-harm or suicide (Daine et al., 2013). For example, users of suicide bulletin boards systems have reported either anti- or pro-suicidal goals, namely to help to recover from suicidality or to help in preparation for suicide (Sueki \& Eichenberg, 2012). Dunlop and colleagues (2011) demonstrated that exposure to suicide stories in online discussion forums was associated with increased suicidal ideation. Longitudinal studies by Sueki reported similar findings, indicating that suicide-related internet use (e.g. accessing information about suicide methods) increased suicidal ideation and depression (Sueki, 2013; Sueki, Yonemoto, Takeshima, \& Inagaki, 2014).

Self-injury content: Non-suicidal self-injury (NSSI) involves the mutilation of one's bodily tissue without suicidal intent and is a pervasive phenomenon among young people (Favazza, 1998; Nock, 2010; Skegg, 2005). Whitlock, Powers, and Eckenrode (2006) studied users of self-injury message boards and found that most of the users were female aged 12 to 20. Lewis and colleagues (2011) carried out a study investigating one hundred YouTube NSSI videos. Their analysis showed that the content of the videos was graphic and the videos were rated favorably by their viewers. The authors argue that the existence of such material in mainstream social media such as YouTube may in fact foster the normalization of self-injury. Exposure to such material is also related to exposure to pro-ana and pro-suicide content; according to the EU Kids Online findings, 10 per cent of 15-16year-olds had visited self-harm websites during past 12 months (Livingstone et al., 2011, p. 98).

\section{Factors of Online Risk Behavior}

Previous studies on online risks and victimization focus on topics such as victimization to cyberbullying (HelwegLarsen, Schütt, \& Larsen 2012; Sourander et al., 2010), cyberharassment (Jones, Mitchell, \& Finkelhorn, 2013; Näsi et al., 2014; Ybarra, Mitchell, \& Korchmaros, 2011), cybercrime (Holt \& Bossler, 2008; Oksanen \& Keipi, 2013; Näsi, Oksanen, Keipi, \& Räsänen, 2015; Yar, 2013) and cyberhate (Hawdon, Oksanen, \& Räsänen, 2014), along with exposure to harmful or disturbing online content. Furthermore, Livingstone and Smith (2014) note that socio-demographic, personal and wider environmental factors affect children and youths' exposure to online risks.

Socio-demographic factors. The EU Kids Online study found no gender differences on exposure to self-injury and suicide sites among 14-16, but girls of the same age were much more likely to witness pro-anorexia content than boys (Livingstone et al. 2011, p. 98). Exposure to self-injury and suicide content, however, is found to become much more prevalent during the later teenage years (Hawton, Saunders, \& O'Connor, 2012), which might also explain online exposure to such phenomenon. Psychological and social problems of young people may escalate, especially after moving out from parental home as youth still living at home tend to be more guarded and supported by their parents (Borowsky, Ireland, \& Resnick, 2001; Helsen, Vollebergh, \& Meeus, 2000). Other potential factors include immigrant background that has been associated with a higher likelihood of online victimization (Näsi et al., 2015).

Online activity. Daily routines and activities are also crucial in understanding online risks (Holt \& Bossler, 2008; Näsi et al., 2015). Internet use in general has been associated with increased online risk exposure in a number of previous studies, illustrating that youth who use online services most are more likely to encounter risks (HelwegLarsen et al., 2012; Livingstone \& Helsper, 2010; Oksanen \& Keipi, 2013).

Personal characteristics. Prior offline victimization has been considered a risk factor for risky online behavior (Livingstone \& Smith, 2014). Research has established a strong link between victimization in both offline and online contexts (Helweg-Larsen et al., 2012; Mitchell et. al, 2011; Sourander et al., 2010). Thus, in other words, young people who have past victimization experiences are more prone to risky online behavior. A study by Livingstone and Görzig (2012) found that facing psychological difficulties may lead to higher risk-taking in the online context. Finally, although very few topical longitudinal studies exist, a study by Noll, Shenk, Barnes, and 
Haralson (2013) found that previous victimization experiences (child maltreatment) led to increased online risktaking, along with risky offline behavior.

Wider environmental factors. Since the online and offline enviroments are increasingly converging, some of the potential roots of risk-taking are found offline. Living in cities, rather than in smaller towns or in suburban areas has been found to influence exposure to lifestyles and routine activities that impact both offline and online behavior (Näsi et al., 2015). In addition to residential differences, a study by Sueki and Eichenberg (2012) focused on a cross-national comparison of suicide bulletin board users in Japan and Germany, however they found no significant differences between the two countries. Helsper, Kalmus, Hasebrink, Sagvari, and De Haan (2013) studied online risk taking, including exposure to self-harm, suicide and pro-eating disorder sites among 9 to 16 year-olds, in a multination European context. According to their findings Nordic countries and The Netherlands belonged in a category of "supported risky explorers". These risky explorers are experienced social media users and encouraged by their parents, but they also encounter more risks including harm-advocating content. Whereas children in the UK, Germany and most Middle and Southern European countries are much more protected by restrictions. These users have lower levels of encountered risks due to higher instances of Internet usage restrictions put into place by parents.

\section{Negative Self-Schemata and Online Behavior}

Our theoretical model is in line with that of Livingstone and Smith's (2014) review, thus we expect that personal vulnerability and previous experiences relate with risky online behavior. We apply the concept on negative selfschemata for the purpose of trying to understand risky online behavior. The concept of self-schema (pl. selfschemata) refers to the cognitive generalization of self. According to Markus (1977, p. 64): "Self-schemata are cognitive generalizations about the self, derived from past experience, that organize and guide the processing of the self-related information contained in an individual's social experience." What and how we think about ourselves will then have an impact on our future behavior, decisions and the information we encounter. Those adopting negative self-schemata are both less happy and less satisfied with their lives and may interpret even seemingly positive things negatively. Negative self-schemata have been associated with depression (Clak \& Beck, 1999), suicidality (Wenzel \& Beck, 2008) and eating-disorders (Stein \& Corte, 2008; Markus, Hamill, \& Sentis, 1987). These studies underline how subjective processing of information is biased. In other words, schemata are the "lens" through which we direct ourselves (Wenzel \& Beck, 2008).

Past experiences have an impact on the development of negative self-schemata. Peer victimization among adolescents, for example, enables this by focusing attention to oneself (Cole et al., 2014). Here, forms of victimization may vary from verbal aggression to physical violence in offline settings. Both cross-sectional and longitudinal studies among adolescents have shown that offline peer victimization has a strong association with depression (Hawker \& Boulton, 2000; Klomek et al., 2008), which in turn is related to suicide and deliberate selfharm (Harrington, 2001). The higher intensity and repetition of victimization experiences are likely to have more negative and permanent impacts on young people.

Self-schemata can therefore be seen as important factors in understanding how and why young people are seeking certain types of online content and communities. Users adopting positive self-schemata may, for example, seek to find gratifying experiences that enforce their positive self-schemata. Conversely negative selfschemata may bias such information processes and instead guide toward harm-advocating online content, including methods of injuring oneself, committing suicide or being pathologically thin. In the online setting, it is common for users to be drawn to those with whom they share some foundational similarity (Oksanen, Hawdon, \& Räsänen, 2014; Oksanen et al., 2015). Harris, McLean, and Sheffield (2009) found that suicidal individuals were more likely to both develop personal relationships online, and be more active in different online forums. A young person facing mental health problems may find a sense of validation or community from like-minded people who have already committed to their goals: a life devoted to anorexia, suicide-ideation or hurting oneself. 


\section{This Study}

Due to the lack of existing topical survey research among adolescents and young adults, our study was set to analyze young respondents who had encountered harm-advocating content online, namely self-injury, suicide and eating disorder sites. Potential risk factors of exposure were based on both empirical research and the theoretical model of negative self-schemata. Our theoretical framework therefore integrated previous research findings on both online risk behavior and online victimization, and we expected that victimization experiences and one's sense of happiness would provide an indirect instrument toward addressing respondents' selfschemata. We were particularly interested examining whether issues associated with negative self-schemata (i.e. victimization experiences and a low sense of happiness) are linked to exposure to such content in a crossnational context. As a result, the following research question were formulated:

RQ1: Can socio-demographic background and online activity predict exposure to harm-advocating content?

RQ2: Do negative self-schemata characteristics associate with exposure to harm-advocating content?

RQ3: What cross-country differences exist in the exposure to harm-advocating online content?

\section{Method}

\section{Participants}

Identical datasets were collected from the United States $(n=1,033)$ and Finland $(n=555)$ in May-June 2013 and from Germany $(n=978)$ and the United Kingdom $(n=999)$ in April 2014. The participants were recruited from a pool of respondents administrated by SSI (Survey Sample International) having volunteered to participate in research surveys. Surveys in the U.S. and UK were in English, whereas in Finland they were in Finnish and German in Germany. Questionnaires were filled out online using a site optimized for both computers and mobile devices. The pool of respondents mirrors geographic area and socio-demographic measures of age, gender and region of each of the four countries (for details, see Lorch 2012; Näsi et al., 2014). Participants ( $n=$ $3565)$ were aged 15 to $30\left(M_{\mathrm{US}}=23.09, S D_{\mathrm{US}}=4.04 ; M_{\mathrm{FIN}}=22.59, S D_{\mathrm{FIN}}=4.21 ; M_{\mathrm{GER}}=23.21, S D_{\mathrm{GER}}=3.97 ; M_{\mathrm{UK}}=\right.$

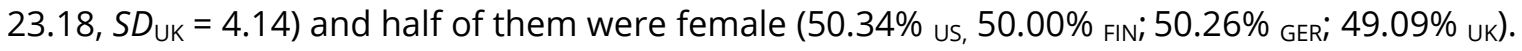

The four countries were selected based on the fact that they are technologically advanced Western societies, but which are also different both societally and culturally. Besides the sizeable differences in population, the four countries differ with respect to their level of welfare provision. The U.S., first of all, is a technologically advanced society which is relatively liberal in terms of legislation concerning online content compared to European countries (Waldron, 2012). Finland here represents a technologically advanced Nordic society where the potential user risks are higher than in Germany and the UK, both of which represent a more restrictive approach to the use of technology (Helsper et al., 2013).

\section{Measures}

Harm-advocating online material. A set of three questions was used to measure exposure to harm-advocating online sites and communities. The respondents were asked whether they had seen the following in the past 12 months (yes/no answer option): 1) "sites about ways of physically harming or hurting yourself" (self-injury material), 2) "Sites about ways of committing suicide" (suicide material), and 3) "sites about ways to be very thin (e.g. sites relating to eating disorders)" (eating disorder material). These three items were used as dependent variables (see Table 1 for percentages of respondents visiting these sites). These questions were adapted from the risk questions included in the EU Kids Online Survey (Livingstone et al., 2011). These items have been operationalized as advocating harm (e.g. pro-eating disorder, Livingstone et al., 2011; pro-suicide, Minkkinen et 
al., 2016), as they address particular methods of harming oneself. Previous studies show that these kinds of instructions are part of pro-anorexia and pro-suicide sites and communities (Biddle et al., 2008; Boero \& Pascoe, 2012; Borzekowski et al., 2010).

Socio-demographic variables. We used a set of five different socio-demographic variables that were comparable across our samples: age, gender, living with parents $(0=$ no, $1=y e s)$, immigrant parent $(0=$ no, $1=y e s)$ and residential information ( $0=$ town or smaller, $1=$ city).

Online activity. Respondents were asked to indicate different social networking sites or Internet services they had used during the past three months. The list of services had 21 items including options on the most popular social networking sites (SNSs) (e.g. Facebook, Twitter, Google+), video sites (YouTube), message and image boards, photo-sharing services and online communication services. These sites and services were summed up into a count measure of scope of online activity. This variable is shown as categorized (quartiles from $1=$ low activity to $4=$ high activity) in the descriptive Table 1 . For the regression models variable was used as continuous (range 1-21; $M_{\mathrm{US}}=6.22, S D_{\mathrm{US}}=3.14 ; M_{\mathrm{FIN}}=6.22, S D_{\mathrm{FIN}}=2.77 ; M_{\mathrm{GER}}=5.55, S D_{\mathrm{GER}}=2.79 ; M_{\mathrm{UK}}=6.27, S D_{\mathrm{UK}}=3.15$ ). Frequency of online activity was measured with a question: "How often do you use the Internet?" Since most of the respondents used the Internet on a daily basis, this variable was categorized as a dummy ( $1=$ several times a day, $0=$ less often). This measure controls the intensity of Internet use.

Happiness. We measured the level of happiness with a widely used single-item measure: "All things considered, how happy would you say you are?" on the scale 1 ("not very true of me") to 10 ("very true of me"). This singleitem measure of wellbeing assessment has been found to be valid in numerous studies in sociology, psychology and economics (e.g. Abdel-Khalek, 2006; Cheung \& Lucas, 2014; Kahneman, Krueger, Schkade, Schwarz, \& Stone 2006; Schwarz \& Clore, 1983). For the purposes of descriptive Table 1, the variable used as categorized as low (1 to 5) and high (6 to 10) level of happiness. For the regression models variable was used as continuous (range 1$\left.10 ; M_{\mathrm{US}}=6.97, S D_{\mathrm{US}}=2.02 ; M_{\mathrm{FIN}}=6.98, S D_{\mathrm{FIN}}=1.97 ; M_{\mathrm{GER}}=6.66, S D_{\mathrm{GER}}=2.20 ; M_{\mathrm{UK}}=6.59, S D_{\mathrm{UK}}=2.06\right)$.

Offline victimization was measured by using a set of three questions (yes/no) designed to measure physical victimization during the past three years: 1) "Has someone bumped into you or touched you in a way that felt insulting to you?", 2) "Has someone you did not know attacked or threatened you in a way that really scared you?", and 3) "Has someone you knew attacked or threatened you in a way that really scared you?". These questions have been previously used in victimization studies (e.g. Vuori, Oksanen, \& Räsänen, 2013). Scale reliability was acceptable $(a=.63)$. We created a count variable that measures exposure to different forms of offline victimization (range 0-3; $M_{\mathrm{US}}=0.58, S D_{\mathrm{US}}=0.89 ; M_{\mathrm{FIN}}=0.62, S D_{\mathrm{FIN}}=0.95 ; M_{\mathrm{GER}}=0.68, S D_{\mathrm{GER}}=0.90 ; M_{\mathrm{UK}}=$ $0.56, S D_{\cup K}=0.89$ ).

Online victimization was measured with three questions (yes/no): 1) "I have personally been the target of hateful or degrading material online", 2) "In your own opinion, have you been a target of harassment online, for example where people have spread private or groundless information about you or shared pictures of you without your permission?", 3) "In the past three years, has someone committed a crime against you online?" These variables have also been determined as valid tools to assess online victimization (e.g. Näsi et al., 2014). These three questions had acceptable inter-item reliability $(\alpha=.60)$. We created a count variable ranging from 0 to 3 to measure online victimization in the same way as was carried out with offline victimization (range $0-3 ; M_{\text {US }}$ $\left.=0.39, S D_{\mathrm{US}}=0.79 ; M_{\mathrm{FIN}}=0.35, S D_{\mathrm{FIN}}=0.66 ; M_{\mathrm{GER}}=0.29, S D_{\mathrm{GER}}=0.58 ; M_{\mathrm{UK}}=0.34, S D_{\mathrm{UK}}=0.75\right)$.

\section{Statistical Analyses}

We used Stata12 software to conduct the analysis. We first report descriptive statistics including percentages of those who have visited sites including harm-advocating online content. Logistic regression analysis models the association between background variables and the binary outcomes concerning harm-advocating online material. The effects of the independent variables are presented as odds ratios (OR) and average marginal effects (AME). AME coefficients provide us with reliable and comparable predictions from a model, while also taking into account other independent variables (Mood, 2010). Model statistics include a likelihood ratio chisquare test $\left(\mathrm{LR} \chi^{2}\right)$ and the pseudo-coefficients of the determination (Nagelkerke Pseudo $\left.R^{2}\right)$. In addition, 
predictive margins indicate the adjusted average probabilities of having seen harm-advocating online material. In addition, we checked robustness by running the models for each country separately (Appendix 1).

\section{Results}

\section{Descriptive Analysis}

In our aggregated data $(n=3656)$, encountering eating disorder content was more common (17.17\%) than encountering self-injury content $(10.88 \%)$ or suicide content $(8.47 \%)$.

Table 1 shows the percentages of those seeing harm-advocating harm online material in each country by independent variables. We can first of all see that the exposure rates in Germany were much lower than in the U.S., Finland and the UK. A Kruskal-Wallis test was conducted to evaluate differences between the countries and they were found in the case of eating disorder content $(\chi(3)=39.23, p<.001)$, self-injury content $(\chi(3)=14.81, p$ $=.002$ ) and pro-suicide material $(\chi(3)=6.80, p=.079)$. Differences between the U.S., Finland and the UK were not statistically significant.

Those respondents who reported lower levels of happiness were significantly more likely to see harmadvocating online material. For example, in the UK and the U.S. one in four participants with a low level of happiness had visited eating disorder sites. We found even higher rates of exposure among both online and offline victims in all of the countries. Exposure was particularly high among those who report multiple forms of either offline or online victimization.

\section{Predictive Analysis}

We ran logistic regression models for different forms of harm-advocating online content. Aggregated data in which all countries were merged were used in the analysis. Separate models for each country are found in the Appendix 1. Table 2 presents the results and full models for each type of content (self-injury, suicide and eating disorders).

Table 2 shows that exposure rates to all three types of harm-advocating material were significantly lower in Germany than in the three other countries. AME figures also show that after controlling socio-demographic background variables, online activity and personal characteristics, exposure to harm advocating content remained significantly lower in Germany (from 6.4 to 11.5 per cent depending on the type of harm-advocating content).

Females were more likely to encounter eating disorder content than males ( $O R=1.75 ; p<0.001)$, while males had slightly higher likelihood of seeing both self-injury (OR 0.78; $p=0.04$ ) and suicide content online (OR 0.76; $p=$ .04). However, the difference was small (ca. 2\%) compared to eating disorder material (6.4\%). Younger age, having an immigrant parent and a city residence were all associated with exposure to self-injury, suicide and eating disorder content.

Scope of online activity was associated with a higher level of exposure to harm advocating online material. In the model, an increase of one site or online service (21 in total) raised the probability of exposure (1.5 increase for eating disorder content, $0.6 \%$ increase for pro-self-incjury content and $0.5 \%$ increase for suicide content). Frequency of online activity was not statistically significant. Those who reported a higher level happiness were less likely to see harm-advocating online content. Higher online and offline victimization raised the likelihood of exposure to harm-advocating online content. As we saw already in the Table 1, those having multiple victimization experiences reported very high exposure figures.

Exposure to harm-advocating materials, measured with the selected items, is relatively well explained by the final models (Nagelkerke Pseudo $\mathrm{R}^{2}$ ranging from $24 \%$ to $26 \%$ ). Wald test statistics showed that happiness and online and offline victimization were the best predictors of harm-advocating content exposure with the highest $z$-values of all variables in the model. 
Table 1: Exposure to Harm-Advocating Online Content in the U.S., Finland, Germany and UK by Independent Variables.

\begin{tabular}{|c|c|c|c|c|c|c|c|c|c|c|c|c|}
\hline & \multicolumn{4}{|c|}{ Self-injury sites (yes, \%) } & \multicolumn{4}{|c|}{ Suicide sites (yes, \%) } & \multicolumn{4}{|c|}{ Eating disorder sites (yes, \%) } \\
\hline & U.S. & Fin & Ger & UK & U.S. & Fin & Ger & UK & U.S. & Fin & Ger & UK \\
\hline All & 12.64 & 12.12 & 4.93 & 14.41 & 9.57 & 9.89 & 4.32 & 10.41 & 22.20 & 20.27 & 7.40 & 20.72 \\
\hline \multicolumn{13}{|l|}{ Gender } \\
\hline Male & 14.26 & 14.08 & 5.58 & 15.32 & 11.72 & 10.11 & 4.75 & 11.79 & 19.14 & 15.16 & 5.58 & 18.66 \\
\hline Female & 10.02 & 11.19 & 4.29 & 13.47 & 8.09 & 9.03 & 3.89 & 8.98 & 21.39 & 29.24 & 9.20 & 22.86 \\
\hline \multicolumn{13}{|l|}{ Age } \\
\hline $15-18$ & 15.27 & 14.41 & 3.55 & 18.75 & 11.45 & 11.02 & 2.84 & 13.19 & 26.72 & 23.73 & 5.67 & 25.00 \\
\hline $19-25$ & 12.90 & 14.08 & 4.83 & 14.74 & 10.25 & 11.91 & 4.63 & 9.83 & 22.97 & 23.83 & 8.69 & 22.12 \\
\hline $25-30$ & 9.58 & 8.81 & 5.73 & 11.96 & 8.68 & 4.40 & 4.46 & 10.12 & 13.17 & 18.24 & 6.05 & 16.56 \\
\hline \multicolumn{13}{|l|}{ Lives with parents } \\
\hline No & 13.38 & 12.93 & 6.19 & 15.85 & 10.87 & 10.29 & 5.67 & 12.20 & 20.90 & 22.69 & 8.25 & 21.68 \\
\hline Yes & 10.39 & 12.00 & 2.70 & 12.67 & 8.55 & 8.00 & 1.89 & 8.22 & 19.40 & 21.14 & 5.39 & 19.56 \\
\hline \multicolumn{13}{|l|}{ Immigrant parent } \\
\hline No & 9.81 & 10.00 & 4.35 & 14.01 & 8.29 & 8.16 & 4.35 & 9.71 & 18.37 & 21.63 & 6.45 & 18.17 \\
\hline Yes & 17.59 & 32.81 & 6.21 & 15.47 & 13.68 & 20.31 & 4.25 & 12.23 & 24.76 & 26.56 & 9.48 & 27.34 \\
\hline \multicolumn{13}{|l|}{ Residence } \\
\hline Town or smaller & 10.20 & 8.24 & 4.06 & 12.58 & 8.03 & 6.74 & 3.29 & 7.81 & 17.57 & 16.85 & 5.22 & 17.14 \\
\hline City & 13.68 & 16.67 & 5.92 & 15.99 & 11.40 & 12.06 & 5.48 & 12.64 & 22.46 & 27.30 & 9.87 & 23.79 \\
\hline \multicolumn{13}{|c|}{ Scope of online activity } \\
\hline Lowest quartile & 10.65 & 8.67 & 5.80 & 11.65 & 9.76 & 8.67 & 4.22 & 8.74 & 11.54 & 12.67 & 7.65 & 13.27 \\
\hline 2 & 8.95 & 8.24 & 1.68 & 10.47 & 5.06 & 4.71 & 3.37 & 8.53 & 15.95 & 19.41 & 5.05 & 16.28 \\
\hline 3 & 13.66 & 15.50 & 2.99 & 12.22 & 9.25 & 12.40 & 2.99 & 7.69 & 24.67 & 27.13 & 6.59 & 19.00 \\
\hline Highest quartile & 16.75 & 21.90 & 12.31 & 25.59 & 16.75 & 15.24 & 8.46 & 18.01 & 34.93 & 34.29 & 13.08 & 38.86 \\
\hline \multicolumn{13}{|c|}{ Frequency of online activity } \\
\hline often & 12.28 & 10.14 & 9.38 & 16.67 & 12.28 & 9.46 & 4.69 & 14.29 & 14.04 & 19.59 & 6.25 & 16.67 \\
\hline Several times a day & 12.11 & 13.55 & 4.62 & 14.21 & 9.75 & 9.61 & 4.29 & 10.05 & 20.64 & 23.15 & 7.48 & 21.09 \\
\hline \multicolumn{13}{|l|}{ Level of happiness } \\
\hline High & 10.00 & 10.51 & 2.41 & 10.99 & 8.23 & 7.48 & 1.42 & 7.55 & 18.61 & 19.63 & 3.55 & 18.68 \\
\hline Low & 19.73 & 21.74 & 11.52 & 23.62 & 16.14 & 18.26 & 11.90 & 18.08 & 26.01 & 33.91 & 17.47 & 26.20 \\
\hline \multicolumn{13}{|c|}{ Online victimization } \\
\hline None & 6.84 & 9.51 & 2.42 & 7.58 & 6.05 & 7.46 & 2.01 & 5.43 & 13.68 & 16.71 & 4.83 & 14.52 \\
\hline 1 & 21.60 & 18.52 & 9.29 & 25.45 & 12.80 & 13.89 & 8.74 & 15.45 & 31.20 & 32.41 & 13.11 & 28.18 \\
\hline 2 & 34.21 & 25.93 & 25.00 & 50.82 & 26.32 & 11.11 & 19.44 & 36.07 & 46.05 & 55.56 & 22.22 & 57.38 \\
\hline 3 & 46.15 & 44.44 & 44.44 & 69.44 & 48.72 & 44.44 & 44.44 & 61.11 & 66.67 & 44.44 & 44.44 & 72.22 \\
\hline \multicolumn{13}{|l|}{ Offline victimization } \\
\hline None & 6.16 & 9.62 & 2.56 & 7.55 & 5.21 & 6.71 & 2.56 & 4.93 & 13.11 & 15.45 & 4.94 & 13.25 \\
\hline 1 & 12.38 & 10.59 & 4.42 & 18.37 & 12.38 & 9.41 & 1.61 & 11.22 & 24.76 & 28.24 & 4.02 & 27.04 \\
\hline 2 & 35.00 & 23.19 & 9.02 & 30.85 & 22.00 & 15.94 & 8.20 & 25.53 & 40.00 & 33.33 & 17.21 & 34.04 \\
\hline 3 & 39.66 & 27.78 & 21.82 & 50.00 & 34.48 & 25.00 & 25.45 & 43.33 & 50.00 & 52.78 & 25.45 & 60.00 \\
\hline
\end{tabular}


Table 2: Logistic Regression Analysis Predicting Exposure to Pro-Self-Hurt Online Content (odd ratios, $p$-values and average marginal effects).

\begin{tabular}{|c|c|c|c|c|c|c|c|c|c|}
\hline & \multicolumn{3}{|c|}{ Self-injury sites } & \multicolumn{3}{|c|}{ Suicide sites } & \multicolumn{3}{|c|}{ Eating disorder sites } \\
\hline & OR & $\mathbf{p}$ & AME & OR & $\mathbf{p}$ & AME & OR & $\mathbf{p}$ & AME \\
\hline \multicolumn{10}{|l|}{ Country } \\
\hline U.S. & Ref. & & & Ref. & & & Ref. & & \\
\hline Finland & 1.18 & 0.379 & 0.015 & 0.97 & 0.865 & -0.003 & 1.21 & 0.203 & 0.026 \\
\hline Germany & 0.36 & 0.000 & -0.064 & 0.39 & 0.000 & -0.052 & 0.30 & 0.000 & -0.115 \\
\hline UK & 1.31 & 0.066 & 0.025 & 1.08 & 0.649 & 0.006 & 1.06 & 0.663 & 0.007 \\
\hline \multicolumn{10}{|c|}{ Socio-demographic background } \\
\hline Gender (female) & 0.78 & 0.043 & -0.020 & 0.76 & 0.040 & -0.018 & 1.75 & 0.000 & 0.064 \\
\hline Age & 0.96 & 0.011 & -0.004 & 0.95 & 0.012 & -0.003 & 0.93 & 0.000 & -0.008 \\
\hline Lives with parents & 0.60 & 0.001 & -0.040 & 0.52 & 0.000 & -0.041 & 0.70 & 0.004 & -0.041 \\
\hline Immigrant parent & 1.45 & 0.005 & 0.031 & 1.22 & 0.181 & 0.013 & 1.38 & 0.004 & 0.038 \\
\hline Residence (city) & 1.10 & 0.442 & 0.008 & 1.20 & 0.182 & 0.012 & 1.33 & 0.006 & 0.033 \\
\hline \multicolumn{10}{|l|}{ Online activity } \\
\hline Scope & 1.09 & 0.000 & 0.006 & 1.07 & 0.000 & 0.005 & 1.14 & 0.000 & 0.015 \\
\hline Frequency (high) & 0.94 & 0.757 & -0.005 & 0.84 & 0.442 & -0.011 & 1.08 & 0.672 & 0.009 \\
\hline \multicolumn{10}{|l|}{ Personal characteristics } \\
\hline Happiness & 0.83 & 0.000 & -0.015 & 0.81 & 0.000 & -0.014 & 0.87 & 0.000 & -0.016 \\
\hline Online victimization & 1.99 & 0.000 & 0.055 & 1.88 & 0.000 & 0.041 & 1.83 & 0.000 & 0.069 \\
\hline Offline victimization & 1.46 & 0.000 & 0.030 & 1.49 & 0.000 & 0.026 & 1.41 & 0.000 & 0.039 \\
\hline Model $\mathbf{n}$ & 3500 & & & 3500 & & & 3500 & & \\
\hline Nagelkerke $\mathbf{R}^{2}$ & 0.253 & & & 0.237 & & & 0.259 & & \\
\hline $\operatorname{LR} \chi^{2}$ & 470.49 & & & 386.01 & & & 590.76 & & \\
\hline Model significance & 0.000 & & & 0.000 & & & 0.000 & & \\
\hline
\end{tabular}

\section{Discussion}

There are only a few survey studies focusing on Internet and social media users who encounter harm-advocating online content. The present cross-national study focused on young people aged 15 to 30 and their exposure to three types of harmful content, namely self-injury, suicide and eating disorders. Based on existing research evidence, we expected potential differences in terms socio-demographics and user characteristics. We based our theory on both previous empirical research, as well as on the concept of negative self-schemata. We then expected that users who had faced more negative experiences in their everyday life and who were generally more unhappy would be more likely to encounter harm-advocating online material.

As our findings show, females were more likely to see eating disorder content, while males saw more pro-selfharm and pro-suicide content. This was expected since eating disorders are more common among the female population (e.g. Fairburn \& Harrison, 2003; Treasure, Claudino, \& Zucker, 2010), whereas suicide rates are much higher among males aged 15 to 29 compared to females of the same age (Skegg, 2005; Hawton et al., 2012; World Health Organization, 2014). Intentional self-harm, however, is more common among young females than young males, though the gender difference decreases with age (Hawton et al., 2012; Skegg, 2005; see also Whitlock et al. 2006). These results might be explained by the fact that some young males, in general, might follow more violent content online (Ybarra et al., 2008). 
Our results also indicated that those living home were less likely to see harm advocating material. This is in line with previous studies showing that primary groups such as family may function as a buffer and protect young people in many ways (Joiner, 2005; Minkkinen et al., 2015). Those having an immigrant parent were more likely to see harm advocating material in general. Previous studies have indicated that an immigrant population is societally more vulnerable, having higher rates of online victimization as well (Näsi et al., 2015).

Our main findings were based on the theory of negative self-schemata. Negative self-schemata were seen as a "lens" through which we direct ourselves (Wenzel \& Beck, 2008). In other words, those young people who are unhappy or have victimization experiences might be more likely to look for harm advocating online content. The results confirmed our expectations, a lower level of happiness and previous online and offline victimization experiences were associated with exposure to harm-advocating online material. Earlier studies have already established that prior negative experiences and psychological problems explain why some young people take risks online (Livingstone \& Görzig, 2012; Noll et al., 2013). Our study expanded this notion. Future studies should continue developing and applying theories on online phenomena, because currently, despite expanding research literature, there are very few theories on online behavior among young people.

Our results also contribute to expanding literature concerning the overlap of online and offline behavior (Helweg-Larsen et al., 2012; Mitchell et. al, 2011). We saw, for example, that those living in cities were more likely to see harm advocating online material. This finding points to the direction of life style factors and other environmental factors in affecting online activity. Future studies should also investigate further how urban realities are mixed with online usage patterns.

Results showed that German users had significantly lower levels of exposure to harm-advocating online content. There were no statistically significant differences between other countries. There are many potential explanations for the lower levels of exposure in Germany. First of all, it is possible that there are considerable differences in users' cultural background. German online usage has been described as "protected by restrictions" (Helsper et al., 2013). Secondly, German speakers are more likely to access German speaking sites, while British and American users engage in sites in English. Furthermore, Finnish users are likely to use English sites extensively as well, mainly because there are only 5.5 million Finnish speakers in the world and as such Finnish language content is far scarcer. The third explanation is connected with the average mental health of young people. German young people aged 15 to 29 have, significantly, relatively low suicide rates especially compared with the Finnish and U.S. rates (World Health Organization, 2014; see also Hawton et al., 2012). This might partially explain the results, especially as we are discussing a relatively pathological online phenomenon.

\section{Limitations and Future Studies}

Our questionnaire did not allow us to determine where exactly the respondents saw the material, which is a limitation. Besides happiness it might have been relevant to measure the general psychological wellbeing of respondents. The cross-sectional design implemented is also one of the limitations for this study, as it does not allow us to determine the causal direction of the detected associations. We cannot say anything about the potential health impacts that self-injury, suicide and eating disorder content poses to online users. The purpose of our study was not, however, to measure the potential negative impact of harm-advocating material, but rather to show who is most likely to encounter such material. As noted earlier, there are only a few longitudinal studies concerning online usage (Dunlop et al., 2011; Noll et al., 2013; Sueki et al., 2014). Future studies should go into the longitudinal direction. We also need more cross-sectional studies, as earlier studies have been mostly based on college samples and other similarly selected samples, and typically from only one country at a time.

\section{Policy Implications}

The main findings of this study are relevant to medical and healthcare practitioners working with adolescents and young adults. They should recognize the existence of online sites and communities that may promote eating disorders, suicide and self-injury and be aware that when individuals with potential mental health problems go online, they are at heightened risk for encountering not only life affirming social support, but also communities that may foster anti-healthy behavior. Entering sites concerning suicide, self-injury and eating disorders could 
also be considered an indicator of other types of potential psychological problems and help should be provided for those in need.

Regulatory practices concerning harm advocating online material have been suggested (Sueki et al., 2014). At the same time it is important to note that user-communities themselves often oppose harmful ideas online, acting as positive support communities (Oksanen et al., 2015). Our results also indicate that prior victimization experiences are potentially the root of the problem. Hence, it might be more useful to target minimizing the harms of victimization.

\section{Conclusion}

Our four-country study analyzed the exposure to three different types of harm-advocating online content (selfinjury, suicide and pro-eating disorders). Although some young people may have life affirming goals when searching for harm advocating material (Sueki \& Eichenberg, 2012; Daine et al., 2013), the general impacts of accessing harm-advocating online material are negative (Sueki et al., 2014). It is therefore important to recognize the existence of harm-advocating and extreme online communities and the relative ease with which young people may encounter this material and the communities producing it. Our results show that users of harm advocating online material are more likely to have lower levels of happiness and past victimization experiences, both online and offline, thus fostering negative self-schemata. The country differences were small among the U.S., Finland and UK, although German adolescents and young adults were significantly less exposed to such material. Our findings underline that despite the global nature of the Internet, there are also contextual factors that may have an impact on online behavior.

\section{References}

Abdel-Khalek, A. M. (2006). Measuring happiness with a single-item scale. Social Behavior and Personality: An International Journal, 34, 139-150. http://dx.doi.org/10.2224/sbp.2006.34.2.139

Arnett, J. J. (2000). Emerging adulthood: A theory of development from the late teens through the twenties. American Psychologist, 55, 469-480.

Barak, A., Boniel-Nissim, M., \& Suler, J. (2008). Fostering empowerment in online support groups. Computers in Human Behavior, 24, 1867-1883. http://dx.doi.org/10.1016/j.chb.2008.02.004

Biddle, L., Donovan, J., Hawton, K., Kapur, N., \& Gunnell, D. (2008). Suicide and the internet. Bmj, 336(7648), 800802. http://dx.doi.org/10.1136/bmj.39525.442674.AD

Boero, N., \& Pascoe, C. J. (2012). Pro-anorexia communities and online interaction: Bringing the pro-ana body online. Body \& Society, 18(2), 27-57. http://dx.doi.org/10.1177/1357034X12440827

Borowsky, I. W., Ireland, M., \& Resnick, M. D. (2001). Adolescent suicide attempts: Risks and protectors. Pediatrics, 107, 485-493. http://dx.doi.org/10.1542/peds.107.3.485

Borzekowski D. L., Schenk S., Wilson J. L., \& Peebles, R. (2010). e-Ana and e-Mia: A content analysis of pro-eating disorder web sites. American Journal of Public Health, 100, 1526-1534.

http://dx.doi.org/10.2105/AJPH.2009.172700

Brechwald, W. A., \& Prinstein, M. J. (2011). Beyond homophily: A decade of advances in understanding peer influence processes. Journal of Research on Adolescence, 21, 166-179. http://dx.doi.org/10.1111/j.1532-

7795.2010.00721.x

Brotsky, S. R., \& Giles, D. (2007). Inside the "pro-ana" community: A covert online participant observation. Eating disorders: The Journal of Treatment \& Prevention, 15, 93-109. http://dx.doi.org/10.1080/10640260701190600 
Cheung, F., \& Lucas, R. E. (2014). Assessing the validity of single-item life satisfaction measures: Results from three large samples. Quality of Life Research, 23, 2809-2818. http://dx.doi.org/10.1007/s11136-014-0726-4

Clak, D. A., \& Beck, A. T. (1999). Scientific foundations of cognitive theory and therapy of depression. NJ: John Wiley \& Sons.

Cole, D. A., Dukewich, T. L., Roeder, K., Sinclair, K. R., McMillan, J., Will, E., ... Felton, J. W. (2014). Linking peer victimization to the development of depressive self-schemas in children and adolescents. Journal of Abnormal Child Psychology, 42, 149-160. http://dx.doi.org/10.1007/s10802-013-9769-1

Custers, K., \& Van den Bulck, J. (2009). Viewership of pro-anorexia websites in seventh, ninth and eleventh graders. European Eating Disorders Review, 17, 214-219. http://dx.doi.org/10.1002/erv.910

Daine, K., Hawton, K., Singaravelu, V., Stewart, A., Simkin, S., \& Montgomery, P. (2013). The power of the Web: A systematic review of studies of the influence of the Internet on self-harm and suicide in young people. PloS one, 8(10), e77555. http://dx.doi.org/10.1371/journal.pone.0077555

Dunlop, S. M., More, E., \& Romer, D. (2011). Where do youth learn about suicides on the Internet, and what influence does this have on suicidal ideation? Journal of Child Psychology and Psychiatry, 52, 1073-1080. http://dx.doi.org/10.1111/j.1469-7610.2011.02416.x

Fairburn, C., \& Harrison, P. J. (2003). Eating disorders. The Lancet, 361, 407-416. http://dx.doi.org/10.1016/S01406736(03)12378-1

Favazza, A. R. (1998). The coming of age of self-mutilation. The Journal of Nervous and Mental Disease, 186, 259268. http://dx.doi.org/10.1097/00005053-199805000-00001

Gavin, J., Rodham, K., \& Poyer, H. (2008). The presentation of "pro-anorexia" in online group interactions. Qualitative Health Research, 18, 325-333. http://dx.doi.org/10.1177/1049732307311640

Harper, K., Sperry, S., \& Thompson, J. K. (2008). Viewership of pro-eating disorder websites: Association with body image and eating disturbances. International Journal of Eating Disorders, 41, 92-95.

http://dx.doi.org/10.1002/eat.20408

Harrington, R. (2001). Depression, suicide and deliberate self-harm in adolescence. British Medical Bulletin, 57(1), 47-60. http://dx.doi.org/10.1093/bmb/57.1.47

Harris, K. M., McLean, J. P., \& Sheffield, J. (2009). Examining suicide-risk individuals who go online for suiciderelated purposes. Archives of Suicide Research, 13, 264-276. http://dx.doi.org/10.1080/13811110903044419

Hawdon, J., Oksanen, A., \& Räsänen, P. (2014), Victims of online hate groups: American youth's exposure to online hate speech. In J. Hawdon, J. Ryan, \& M. Lucht (Eds.), The causes and consequences of group violence: From bullies to terrorists (pp. 165-182). Lanham: Lexington Books.

Hawker, D. S. J., \& Boulton, M. J. (2000). Twenty years' research on peer victimization and psychosocial maladjustment: A meta-analytic review of cross-sectional studies. Journal of Child Psychology and Psychiatry, 41, 441-455. http://dx.doi.org/10.1111/1469-7610.00629

Hawton, K., Saunders, K. E., \& O'Connor, R. C. (2012). Self-harm and suicide in adolescents. The Lancet, 379, 23732382. http://dx.doi.org/10.1016/S0140-6736(12)60322-5

Helsen, M., Vollebergh, W., \& Meeus, W. (2000). Social support from parents and friends and emotional problems in adolescence. Journal of Youth and Adolescence, 29, 319-335. http://dx.doi.org/10.1023/A:1005147708827 
Helsper, E. J., Kalmus, V., Hasebrink, W., Sagvari, B, \& De Haan, J. (2013). Country Classification: Opportunities, Risks, Harm and Parental Mediation. LSE, London: EU Kids Online.

Helweg-Larsen, K., Schütt, N., \& Larsen, H. B. (2012). Predictors and protective factors for adolescent Internet victimization: Results from a 2008 nationwide Danish youth survey. Acta Paediatrica, 101, 533-539.

Holt, T. J., \& Bossler, A. M. (2008). Examining the applicability of lifestyle-routine activities theory for cybercrime victimization. Deviant Behavior, 30, 1-25. http://dx.doi.org/10.1080/01639620701876577

Joiner, T. E. (2005). Why people die by suicide. Cambridge, MA: Harvard University Press.

Jones, L. M., Mitchell, K. J., \& Finkelhor, D. (2013). Online harassment in context: Trends from three Youth Internet Safety Surveys (2000, 2005, 2010). Psychology of Violence, 3, 53-69. http://dx.doi.org/10.1037/a0030309

Juarascio, A.S., Shoaib, A., \& Timko, C.A. (2010). Pro-eating disorder communities on social networking sites: a content analysis. Eating disorders: The Journal of Treatment \& Prevention, 18, 393-407.

http://dx.doi.org/10.1080/10640266.2010.511918

Kahneman, D., Krueger, A. B., Schkade, D., Schwarz, N., \& Stone, A. A. (2006). Would you be happier if you were richer? A focusing illusion. Science, 312, 1908-1910. http://dx.doi.org/10.1126/science.1129688

Kemp, C. G., \& Collings, S. C. (2011). Hyperlinked suicide. Crisis: The Journal of Crisis Intervention and Suicide Prevention, 32, 143-151.

Klomek, A., Sourander, A., Kumpulainen, K., Piha, J., Tamminen, T., Moilanen, I., . . Gould, M. (2008). Childhood bullying as a risk for later depression and suicidal ideation among Finnish males. Journal of Affective Disorders, 109, 47-55. http://dx.doi.org/10.1016/j.jad.2007.12.226

Koivumaa-Honkanen, H., Honkanen, R., Koskenvuo, M., \& Kaprio, J. (2003). Self-reported happiness in life and suicide in ensuing 20 years. Social Psychiatry and Psychiatric Epidemiology, 38, 244-248.

http://dx.doi.org/10.1007/s00127-003-0625-4

Lewis, S. P., \& Arbuthnott, A. E. (2012). Searching for thinspiration: The nature of internet searches for pro-eating disorder websites. Cyberpsychology, Behavior, and Social Networking, 15, 200-204.

Lewis, S. P., Heath, N. L., Michal, N. J., \& Duggan, J. M. (2012). Non-suicidal self-injury, youth, and the Internet:

What mental health professionals need to know. Child and adolescent psychiatry and mental health, 6, article: 13.

Lewis, S. P., Heath, N. L., St Denis, J. M., \& Noble, R. (2011). The scope of nonsuicidal self-injury on YouTube. Pediatrics, 127, e552-e557. http://dx.doi.org/10.1542/peds.2010-2317

Livingstone, S., \& Görzig, A. (2012). Sexting. In S. Livingstone, L. Haddon \& A. Görzig (Eds.), Children, Risk and Safety on the Internet: Research and policy challenges in comparative perspective (pp. 151-164). Bristol: The Policy Press.

Livingstone, S., Haddon, L., Görzig, A., \& Ólafsson, K. (2011). Risks and safety on the internet: The perspective of European children: Full findings and policy implications from the EU Kids Online survey of 9-16 year olds and their parents in 25 countries. EU Kids Online. LSE, London: EU Kids Online.

Livingstone, S., \& Helsper, E. (2010). Balancing opportunities and risks in teenagers' use of the internet: the role of online skills and internet self-efficacy. New Media \& Society, 12, 309-329.

Livingstone, S., \& Smith, P. K. (2014). Annual research review: Harms experienced by child users of online and mobile technologies: The nature, prevalence and management of sexual and aggressive risks in the digital age. Journal of Child Psychology and Psychiatry, 55, 635-654. http://dx.doi.org/10.1111/jcpp.12197 
Lorch, J. (2012). Sample blending: $1+1>2$. Survey Sampling International. Retrieved from

https://www.surveysampling.com/site/assets/files/1584/sample-blending-1-1-2.pdf

Luxton, D. D., June, J. D., \& Fairall, J. M. (2012). Social media and suicide: A public health perspective. American Journal of Public Health, 102, S195-S200. http://dx.doi.org/10.2105/AJPH.2011.300608

Markus, H. (1977). Self-schemata and processing information about the self. Journal of Personality and Social Psychology, 35, 63-78. http://dx.doi.org/10.1037/0022-3514.35.2.63

Markus, H., Hamill, R., \& Sentis, K. P. (1987). Thinking fat: Self-schemas for body weight and the processing of weight relevant information. Journal of Applied Social Psychology, 17, 50-71. http://dx.doi.org/10.1111/j.1559-

1816.1987.tb00292.x

Minkkinen, J., Oksanen, A., Näsi, M., Keipi, T., Kaakinen, M., Keipi, T., \& Räsänen, P. (2016). Does social belonging to primary groups protect young people from the effects of pro-suicide sites? Crisis: The Journal of Crisis Intervention and Suicide Prevention, 37(1), 31-41. http://dx.doi.org/10.1027/0227-5910/a000356

Mitchell, K. J., Finkelhor, D., Wolak, J., Ybarra, M. L., \& Turner, H. (2011). Youth internet victimization in a broader victimization context. Journal of Adolescent Health, 48, 128-134.

http://dx.doi.org/10.1016/j.jadohealth.2010.06.009

Mood, C. (2010). Logistic regression: Why we cannot do what we think we can do, and what we can do about it. European Sociological Review, 26, 67-82. http://dx.doi.org/10.1093/esr/jcp006

Näsi, M., Oksanen, A., Keipi, T., \& Räsänen, P. (2015). Cybercrime victimization among young people: A multinational study. Journal of Scandinavian Studies in Criminology and Crime Prevention, 16, 203-210.

http://dx.doi.org/10.1080/14043858.2015.1046640

Näsi, M., Räsänen, P., Oksanen, A., Hawdon, J., Keipi, T., \& Holkeri, E. (2014). Association between online harassment and exposure to harmful online content: A cross-national comparison between the United States and Finland. Computers in Human Behavior, 41, 137-145. http://dx.doi.org/10.1016/j.chb.2014.09.019

Nock, M. K. (2010). Self-injury. Annual Review of Clinical Psychology, 6, 339-363.

http://dx.doi.org/10.1146/annurev.clinpsy.121208.131258

Noll, J. G., Shenk, C. E., Barnes, J. E., \& Haralson, K. J. (2013). Association of maltreatment with high-risk internet behaviors and offline encounters. Pediatrics, 131, e510-e517. http://dx.doi.org/10.1542/peds.2012-1281

Norris, M. L., Boydell, K. M., Pinhas, L., \& Katzman, D. K. (2006). Ana and the Internet: A review of pro-anorexia websites. International Journal of Eating Disorders, 39, 443-447. http://dx.doi.org/10.1002/eat.20305

Obst, P., \& Stafurik, J. (2010). Online we are all able bodied: Online psychological sense of community and social support found through membership of disability-specific websites promotes well-being for people living with a physical disability. Journal of Community and Applied Social Psychology, 20, 525-531.

http://dx.doi.org/10.1002/casp.1067

Oksanen, A., Garcia, D., Sirola, A., Näsi, M., Kaakinen, M., Keipi, T., \& Räsänen, P. (2015). Pro-anorexia and antipro-anorexia videos on YouTube: Sentiment analysis of user responses. Journal of Medical Internet Research, 17(11):e256. DOI: 10.2196/jmir.5007. http://dx.doi.org/10.2196/jmir.5007

Oksanen, A., Hawdon, J., \& Räsänen, P. (2014). Glamorizing rampage online: School shooting fan communities on youtube. Technology in Society, 39, 55-67. http://dx.doi.org/10.1016/j.techsoc.2014.08.001

Oksanen, A., \& Keipi, T. (2013). Young people as victims of crime on the internet: A population-based study in Finland. Vulnerable Children \& Youth Studies, 8, 298-309. 
Portzky, G., van Heeringen, K., \& Vervaet, M. (2014). Attempted suicide in patients with eating disorders. Crisis: The Journal of Crisis Intervention and Suicide Prevention, 35, 378-387. http://dx.doi.org/10.1027/0227-

5910/a000275

Rajagopal, S. (2004). Suicide pacts and the internet. Bmj, 329(7478), 1298-1299.

http://dx.doi.org/10.1136/bmj.329.7478.1298

Recupero, P. R., Harms, S. E., \& Noble, J. M. (2008). Googling suicide: Surfing for suicide information on the Internet. Journal of Clinical Psychiatry, 69, 878-888. http://dx.doi.org/10.4088/JCP.v69n0601

Rodgers, R. F., Skowron, S., \& Chabrol, H. (2012). Disordered eating and group membership among members of a pro-anorexic online community. European Eating Disorders Review, 20, 9-12. http://dx.doi.org/10.1002/erv.1096

Schulenberg, J. E., \& Zarrett, N. R. (2006). Mental health during emerging adulthood: Continuity and discontinuity in courses, causes, and functions. In J. Arnett \& J. L. Tanner (Eds.), Emerging adults in America: Coming of age in the 21st century (pp. 135-172). Washington, DC, US: American Psychological Association.

Schwarz, N., \& Clore, G. L. (1983). Mood, misattribution, and judgments of well-being: Informative and directive functions of affective states. Journal of Personality and Social Psychology, 45, 513-523.

http://dx.doi.org/10.1037/0022-3514.45.3.513

Skegg, K. (2005). Self-harm. The Lancet, 366, 1471-1483. http://dx.doi.org/10.1016/S0140-6736(05)67600-3

Sourander, A., Klomek, A. B., Ikonen, M., Lindroos, J., Luntamo, T., Koskelainen, M., . . Helenius, H. (2010). Psychosocial risk factors associated with cyberbullying among adolescents: A population-based study. Archives of General Psychiatry, 67, 720-728. http://dx.doi.org/10.1001/archgenpsychiatry.2010.79

Stein, K. F., \& Corte, C. (2008). The identity impairment model: A longitudinal study of self-schemas as predictors of disordered eating behaviors. Nursing Research, 57, 182-190.

http://dx.doi.org/10.1097/01.NNR.0000319494.21628.08

Sueki, H. (2013). The effect of suicide-related Internet use on users' mental health: A longitudinal study. Crisis: The Journal of Crisis Intervention and Suicide Prevention, 34, 348-353. http://dx.doi.org/10.1027/0227-5910/a000201

Sueki, H., \& Eichenberg, C. (2012). Suicide bulletin board systems comparison between Japan and Germany. Death Studies, 36, 565-580. http://dx.doi.org/10.1080/07481187.2011.584012

Sueki, H., Yonemoto, N., Takeshima, T., \& Inagaki, M. (2014). The impact of suicidality-related internet use: A prospective large cohort study with young and middle-aged internet users. PloS one, 9(4), e94841. http://dx.doi.org/10.1371/journal.pone.0094841

Swanson, S. A., Crow, S. J., Le Grange, D., Swendsen, J., \& Merikangas, K. R. (2011). Prevalence and correlates of eating disorders in adolescents: Results from the national comorbidity survey replication adolescent supplement. Archives of General Psychiatry, 68, 714-723. http://dx.doi.org/10.1001/archgenpsychiatry.2011.22

Tanis M. (2007). Online social support groups. In: A. Joinson, K. McKenna, T. Postmes, \& U. Reips (Eds.). The Oxford handbook of internet psychology (pp. 139-153). Oxford: Oxford University Press.

Treasure, J., Claudino, A. M., \& Zucker, N. (2010). Eating disorders. The Lancet, 375, 583-593. http://dx.doi.org/10.1016/S0140-6736(09)61748-7

Vuori, M., Oksanen, A., \& Räsänen, P. (2013). Local responses to collective and personal crime after school shootings. Crime, Law and Social Change, 59, 225-242. http://dx.doi.org/10.1007/s10611-013-9421-6 
Waldron, J. (2012), The harm in the hate speech. Cambridge, Massachusetts \& London, England: Harvard University Press.

Wenzel, A., \& Beck, A. T. (2008). A cognitive model of suicidal behavior: Theory and treatment. Applied \& Preventive Psychology, 12, 189-201. http://dx.doi.org/10.1016/j.appsy.2008.05.001

Whitlock, J. L., Powers, J. L., \& Eckenrode, J. (2006). The virtual cutting edge: The internet and adolescent selfinjury. Developmental Psychology, 42, 407-417. http://dx.doi.org/10.1037/0012-1649.42.3.407

World Health Organization. (2014). Preventing Suicide: A Global Imperative. Geneva: WHO Press.

Yar, M. (2013). Cybercrime and society. London: Sage.

Ybarra, M. L., Diener-West, M., Markow, D., Leaf, P. J., Hamburger, M., \& Boxer, P. (2008). Linkages between Internet and other media violence with seriously violent behavior by youth. Pediatrics, 122, 929-937.

http://dx.doi.org/10.1542/peds.2007-3377

Ybarra, M. L., Mitchell, K. J., \& Korchmaros, J. D. (2011). National trends in exposure to and experiences of violence on the Internet among children. Pediatrics, 128, 1376-1386. http://dx.doi.org/10.1542/peds.2011-0118

\section{Appendix}

Table A1: Exposure to Harm-Advocating Online Content in the U.S., Finland, Germany and UK (Logistic Regression Analysis Models for Each Country, Average Marginal Effects).

\begin{tabular}{|c|c|c|c|c|c|c|c|c|c|c|c|c|}
\hline & \multicolumn{4}{|c|}{ Self-injury sites (AME) } & \multicolumn{4}{|c|}{ Suicide sites (AME) } & \multicolumn{4}{|c|}{ Eating disorder sites (AME) } \\
\hline & U.S. & Fin & Ger & UK & U.S. & Fin & Ger & UK & U.S. & Fin & Ger & UK \\
\hline \multicolumn{13}{|c|}{ Socio-demographic background } \\
\hline Gender (female) & -0.027 & -0.031 & -0.015 & 0.000 & -0.026 & -0.011 & -0.010 & -0.016 & 0.052 & 0.113 & 0.035 & 0.078 \\
\hline Age & -0.005 & -0.007 & 0.000 & -0.004 & -0.002 & -0.013 & -0.001 & -0.001 & -0.012 & -0.008 & -0.003 & -0.009 \\
\hline Lives with parents & -0.044 & -0.059 & -0.022 & -0.041 & -0.030 & -0.081 & -0.036 & -0.037 & -0.051 & -0.045 & -0.021 & -0.032 \\
\hline Immigrant parent & 0.039 & 0.163 & 0.004 & 0.009 & 0.020 & 0.078 & -0.015 & 0.018 & 0.030 & 0.030 & 0.016 & 0.068 \\
\hline Residence (city) & 0.011 & 0.051 & 0.004 & -0.019 & 0.013 & 0.036 & 0.005 & 0.000 & 0.023 & 0.077 & 0.029 & 0.006 \\
\hline \multicolumn{13}{|l|}{ Online activity } \\
\hline Scope & 0.002 & 0.017 & 0.001 & 0.011 & 0.005 & 0.007 & 0.000 & 0.008 & 0.018 & 0.022 & 0.003 & 0.021 \\
\hline Frequency (high) & 0.005 & 0.029 & -0.024 & -0.049 & -0.028 & 0.014 & 0.021 & -0.052 & 0.018 & 0.002 & 0.038 & -0.031 \\
\hline \multicolumn{13}{|l|}{ Personal characteristics } \\
\hline Happiness & -0.012 & -0.016 & -0.012 & -0.020 & -0.011 & -0.016 & -0.014 & -0.014 & -0.015 & -0.021 & -0.021 & -0.005 \\
\hline Online victimization & 0.045 & 0.025 & 0.036 & 0.092 & 0.044 & 0.010 & 0.028 & 0.061 & 0.081 & 0.057 & 0.030 & 0.100 \\
\hline Offline victimization & 0.044 & 0.031 & 0.012 & 0.036 & 0.027 & 0.027 & 0.016 & 0.034 & 0.033 & 0.056 & 0.022 & 0.045 \\
\hline Model n & 1000 & 528 & 973 & 999 & 1000 & 528 & 973 & 999 & 1000 & 528 & 973 & 999 \\
\hline Nagelkerke $\mathbf{R}^{2}$ & 0.216 & 0.220 & 0.247 & 0.324 & 0.189 & 0.181 & 0.307 & 0.196 & 0.223 & 0.224 & 0.240 & 0.275 \\
\hline $\operatorname{LR} \chi^{2}$ & 120.80 & 65.93 & 81.36 & 200.99 & 95.27 & 46.58 & 93.66 & 160.90 & 152.999 & 83.501 & 100.916 & 192.9 \\
\hline Model significance & 0.000 & 0.000 & 0.000 & 0.000 & 0.000 & 0.000 & 0.000 & 0.000 & 0.000 & 0.000 & 0.000 & 0.000 \\
\hline
\end{tabular}

Note. Bold font indicates statistical significance at 0.05-level 


\title{
Correspondence to:
}

Atte Oksanen

School of Social Sciences and Humanities

University of Tampere

Tampere

Finland FI-33014

Email: atte.oksanen(at)uta.fi

\begin{abstract}
About authors
Atte Oksanen, Dr. Soc. Sci., is professor of social psychology at the University of Tampere, Finland. His research focuses on emerging technologies and social interaction. He has published in a variety of areas including youth studies, drug and alcohol research and criminology.

Matti Näsi, Dr. Soc. Sc., is a Postdoctoral researcher at the Institute of Criminology and Legal Policy at University of Helsinki, Finland. His research focuses on the impacts of information and communication technologies on society and social life, with current emphasis on implications concerning harmful online content.

Jaana Minkkinen, Dr.Soc.Sc., is a Postdoctoral researcher in Health Sciences at University of Tampere, Finland. Her research interests contain well-being of children and young people, especially intertwined relationships between mental health and social relationships.

Teo Keipi, Dr. Soc.Sc., is a Postdoctoral researcher at the Department of Social Research at Turku University in Turku, Finland. His current research focuses on online hate content production and exposure, including the structural dynamics of social media that affect interaction and victimisation.

Markus Kaakinen, M.Soc.Sc., is a doctoral researcher at the School of Social Sciences and Humanities at the University of Tampere, Finland. His research focuses on social psychology of education and online interaction.

Pekka Räsänen, Dr. Soc.Sc., is professor of economic sociology at the University of Turku, Finland. He has published widely on research methods, mass violence, culture, and consumer behavior. His current research focuses on the new information and communication technologies.
\end{abstract}

